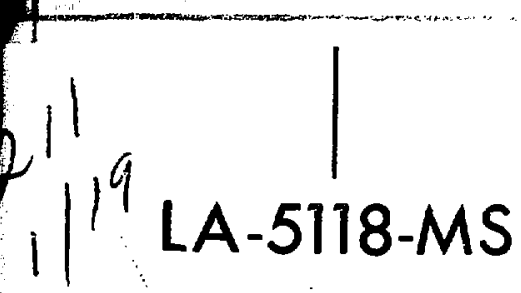

INFORMAL REPORT

$$
\text { th. } 2426
$$

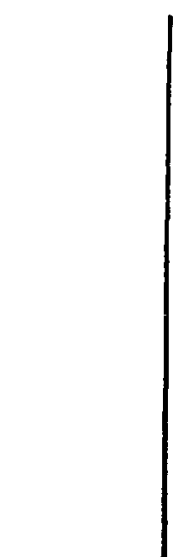

MCA FOCAL: A Real-Time Programming System for Multichannel Analysis on a PDP-9/PDP-15 Computer 
This report was prepared as an account of work sponsored by the United States Government. Neicher the United States nor the United States Atomic Energy Commission, nor any of their employees, nor any of their contractors, subciantractors, or their employees, makes any warranty, express or implied, or assumes any legal liability or responsibility for the accuracy, completeness or usefuiness of any information, apparatus, product or process disclosed, or represenis that its use would not infringe privately owned rights.

In the interest of prompt distribution, this LAMS report was not edited by the Technical Information staff.

Printed in the United States of America. Available from National Technical Information Service

U. S. Department of Commerce 5285 Port Royal Road

Springfield, Virginia 22151

Price: Printed Copy \$3.00; Microfiche $\$ 0.95$ 


\author{
LA.5118-MS \\ Informal Report \\ UC.32 \\ ISSUED: December 1972
}

NOTICE

This report vas prepared as an account of work sponsored by the United States Government. Nelther the United States nor the United States Atomic Energy Commission, nor ony of their employees, nor any of their contractors, subcontractors, or their employees, makes any warsanty, express or implind, or asumes any mel lility or pletenes or usefulness of any information, pletenesa or userulness of any information, epparatus, product or process disclosed, or represents that its use would not infringe privately owned rights.

\title{
MCA FOCAL: A Real-Time Programming
for Multichannel Analysis on a PDP-9/PDP-15 Computer
}

\author{
by \\ Larry V. East \\ Paul M. Aebersold* \\ of the \\ Nuclear Analysis Research Group
}

*Present address: Department of Biophysics, University of California, Berkeley, CA.

Work supported by the U.S. AEC Division of Nuclear Materials Security

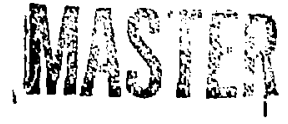




\section{CONTENTS}

$\begin{array}{lc}\text { LIST OF TABLES } & \text { PAGE } \\ \text { LIST OF FIGURES } & \text { iii } \\ \text { iii }\end{array}$

I. INTRODUCTION

II. DATA DISPLAY 2

III. FUNCTIONAL CONTROL PANEL $\quad 2$
A. Toggle Switches 2
B. Rotary Switches ․ 2
C. Push Buttons 3
D. Thumb Switches 3
E. Status Lamps 3

IV. MCA FOCAL FUNCTIONS

A. FADC $\quad$ 3

B. FSTP 5

C. FT:IM

D. FPSH 5

E. FRSW

F. FZER

G. FCUR 5

H. FDTP 6

I. FMCA 7

J. FSWH 7

K. FRDC 7

L. FPRC 7

M. FODT

N. FDT 7

O. FPLT, FPPL, and FCON 7

P. FCOM 7

Q. FCNT 8

V. MCA FOCAL PROGRAM EXAMPLE

$\begin{array}{ll}\text { ACKNOWLEDGMENTS } & 10\end{array}$

$\begin{array}{ll}\text { REFERENCES } & 10\end{array}$

APPENDICES
A LISTING OF PHA PROGRAM
B LOADING AND RUNNING MCA FOCAL
C MCA FOCAL IMPLEMENTATION 16 
LIST OF TABLES

$\begin{array}{lrlr}\text { SECTION } & \text { T.BLE } & \text { PAGE } \\ \text { III. } & \text { I } & \text { CONTROL PANEL TOGGLE SWITCHES } & 3 \\ \text { IV. } & \text { II } & \text { MCA FOCAL INTERNAL FUNCTIONS } & 4 \\ \text { IV. } & \text { III } & \text { MCA FOCAL EXTERNAL FUNCTIONS } & 4 \\ \text { IV. } & \text { IV } & \text { EXAMPLES OF SOME INSTRUCTIONS THAT } & 8 \\ & & \text { MAY BE EXECUTED BY FUNCTION FCOM }\end{array}$

APPENDIX

B.

B-I. MCA HOCAL .DAT SLOT USAGE

14

C.

C-I. CONDITIONAL ASSEMBLY PARAMETERS FOR FOCALM

16

LIST OF FIGURES

SECTION

FIGURE

PAGE

III.

1. FUNCTIONAL CONTROL PANEL OVERLAY

2

V.

2. SAMPLE FLOT PRODUCED BY PHAPLT.

9 
MCA FOCAL: A REAL-TIME PROGRAMMING SYSTEM FOR

MULI ICHANNEL ANALYSIS ON A PDP-9/PDP-15 COMPUTER

by

Larry V. East

and

Pául M. Aebersold*

\begin{abstract}
A programming system based on a modified FOCAL interpreter is described for a PDP-9/PDP-15 computer equipped with specific hardware. User programs written in FOCAL may be used to control the acquisition of multichannel pulse height data and perform data analysis. A switch panel and CRT display with a light pen are utilized to allow the user a high degree of interaction with the data acquisition routines.
\end{abstract}

\section{INTRODUCTION}

MCA (Multi-Channel Analysis) FOCAL**; is a modification of Digital Equipment Corporation's FOCAL (FOrmula CALculator) interactive prcgramming language. The software is designed to be used with a 16K PDP-9, PDP-9/L, or PDP-15 computer equipped with DEC-tape, display and light pen, Functional Control Panel**\% (FCP) and dual Analogto-Digital Converters $* * * *$ (ADCs). Additional peripheral devices, such as a line printer and digital plotter, may also be utilized.

"Tennecomp Systems, Inc., Oak Ridge, TN. Present address: Dept. of Biophysics, University of California, Berkeley, CA.

*FOCAL, PDP, and DEC are registered trademarks of the Digital Equipment Corporation, Maynard, MA.

***Tennecomp Systems, Inc., Model TP-1347.

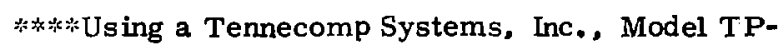
1517 ADC Interface.
Up to $4096(4 \mathrm{~K})$ channels of pulse height data may be acquired via one or two ADCs and stored in the upper $4 \mathrm{~K}$ of computer memory. The ADCs may be staried and stopped under software control via FOCAL function calls, or by push buttons on the Functional Control Panel (FCP). The data region is displayed on a CRT display, which is controlled by the FCP. FOCAL programs have full access to the data region of memory for bidirectional transfers.

The syntax of MCA FOCAL is the same as FOCAL LSL, and the reader is referred to the FOCAL LSL Programming Manual for a description of the language. ${ }^{1}$ However. Sec. IV of this report describes in detail the special functions implemented in MCA FOCAL. Section II describes the data display capabilities, ant Sec. III describes the use of the control panel. A EOCAL program for performing simple pulse height analys is functions is 
described in Sec. V. MCA FOCAL is designed to operate under control of the PDP-9/PDP-15 Advanced Monitor Software System, ${ }^{2}$ and the reader is assumed to have some familiaity with the basic operation of this system.

\section{DATA DISPLAY}

Data from the $4 \mathrm{~K}$ data region of memory are displayed through a 256-word display buffer. If mcre than 256 data channels are displayed, then each display point represents the largest number contained in a group of $\mathrm{N}$ data channels, where $\mathrm{N}=2$ for 512 channels up to 16 for $\$ 096$ channels. The display routine is entered via a clock interrupt approximately every $1 / 30 \mathrm{sec}$, and may be disabled by a FCP switch in order to decrease the execution time of FOCAL programs.

Two vertical cursors are shown on the display and may be used to mark regions of data for analysis, display expansion, etc. The cursor with the fins point spacing is the "active" cursor and may be positioned to any displayed data point by touching that point with the light pen. The inactive cursor may be made active by pointing to the cursor with the light pen. The lower cursor is dominant and may be positioned at any displayed data point. The upper cursor cannot be positioned below the lower
- cursor; should this be attempted, the upper cursor will remain at the lower cursor position. The data channels marked by the cursors may be determined by the FOCAL function FCUF(N), where $\mathrm{N}=1$ for the lower cursor and 2 for the upper cursor (see Sec. IV-G).

\section{FUNCTIONAL CONTROL PANEL}

The FCP contains a series of switches for input to the computer and status lamps for output. Labels are mounted on removable overlays for each computer program utilizing the control panel. The general MCA FOCAL panel overlay is shown in Fig. 1.

The uses of the various switches and status lamps are described in the following paragraphs. A. Toggle Switches

Toggle switches $\mathrm{S} 1$ and $\mathrm{S} 8$ are not used; switches S2-S7 are used as described in Table I. B. Rotary Switehes

The positions of the four rotary switches $R 1$ to $\mathrm{R} 4$ may be determined via the FOCAL function FRSW (see Ser. IV-E). The first rotary switch, $R 1$, has no specific use and may be used to set a FOCAL variable via a function call of the form SET VAR=FRSW(1).

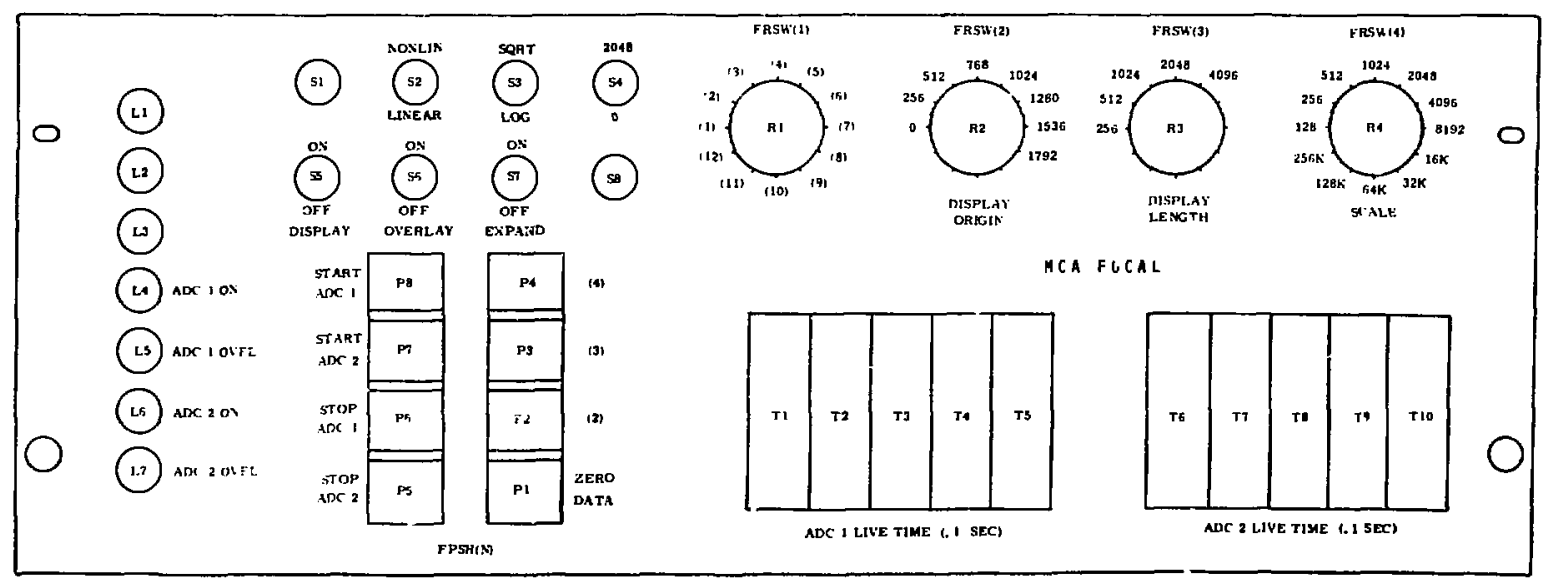

Fig. 1. Functional control panel overlay for use with MCA FOCAL. 


\section{TABLE I}

CONTROL PANEL TOGGLE SWITCHES

Switch No.

S2

S3

S5̄

56

S7

\section{Use}

Selects either a linear or nonlinear vertical scale for the data display. If the nonlinear setting is selected, the data will be displayed with the type of scale determined by switch S3.

Selects either a square root or logarithmic vertical scale for the display when switch $\mathrm{S} 2$ is set to nonlinear.

In conjunction with rotary switch R2, specifies the channel origin for the display. The number of channels specified by rotary switch R2 is added to the offset (0 or 2048) specified by this switch to obtain the display origin.

Initiates the displaying of data channels specified by rotary switches R2 and R3. The origin and length of the display remain fixed regardless of the settings of R2 and R3 until this switch is reset (turned off and then back on). May be left off to disable the display for faster execution of FOCAL programs.

Overlays the expanded display with the corresponding data channels from the data region specified by R2 and R3. Effective only when in expand mocie (switch S7 on).

Expands the horizontal display scale to display 128 channels starting with the channel marked by the lower display cursor.

Switches R2 and R3 are used to set the origin and length, respectively, of the region of data to be displayed. New settings of these switches will not affect the display (except when in the overlay mode) until switch S5 is reset. Switch R4 is used to set the vertical display scaie.

C. Push Buttons

Push button P1 is used to zero that portion of the data region currently shown on the full (not
- expanded) display. P8 and P7 are used to enable ADCs 1 and 2, respectively, for preset times determined by the thumb switches. P5 and P6 are used to disable the ADCs. The status of any one of the eight push buttons may be detmined by the FOCAL function FPSH(N) (see Sec. IV-D).

D. Thumb Switches

Thumb switches are used to set the preset live times for the ADCs when they are enabled by push buttons P7 and P8. T1 thru T5 are used to set the live-count time for ADC 1 in units of $0.1 \mathrm{sec}$, and T6 thru T10 are used with ADC 2. Note that the preset times are not determined by the thumb switches when the ADCs are enabled under software control by the function FADC.

\section{E. Siatus Lamps}

Lamps L1 thru L3 are not used. L4 will be on whenever ADC 1 is enabled; L5 will come on if the maximum count of 262,143 has been exceeded in any data channel associated with ADC I (ADC 1 will remain enabled). L5 will be cleared (turned off) when the data region is zeroed, or when ADC 1 is reenabled. Status lamps L6 and L7 are used to indicate the enabled and overflow status of ADC 2.

\section{MCA FOCAL FUNCTIONS}

The standard FOCAL ISL internal functions listed in Table II are also available in MCA FOCAL. In addition, the 19 special purpose "external" functions listed in Table III are available in MCA FOCAL; the last ten or these functions are also available in FOCAL LSL. Use of the external functions is described in detail in the following sections. Remember that zero arguments need not be specified in function calls, provided that the proper number of commas are retained (refer to Chap. IV of Ref. 1).

\section{A. FADC}

This function is used to enable one of the two ADCs for a specified live-count time. The form of the function call is:

SET DUM=FADC(N, TIM) 
TABLE II

MCA FOCAL INTERNAL FUNCTIONS

Symbol Function Description

FSQT $(X) \quad$ Square Root $X$ must be $\geq 0$.

FABS(X) Absolute Value Sign of $\mathrm{X}$ ignored.

FSGN(X) Sign Part Return +1 for positive

$X,-1$ for negative $X$.

$\operatorname{FITR}(\mathrm{X}) \quad$ Integer Part

Returns the integer part of $X$ (no rounding performed).

FRAN() Random Number Generates a pseudoGenerator random number between +1 and -1 . A nonzero argument may be used to initialize the random number sequence.

FEXP(X) Exponential Computes $e^{x}(e=$ 2. $718281, \ldots)$.

FSIN(X) Sine

$\mathrm{FCOS}(\mathrm{X}) \quad$ Cosine

FATN(X) Arc Tangent

FLOG(X) Natural Logarithm

Sine of angle $X$ expressed in radians.

$X$ expressed in radians.

Generates the angle in radians for which $X$ is the tangent.

Computes $\log _{e}(X)$; $\mathrm{X}$ must be $>0$.

FLOC() Core Locations Returns the number of core locations available to the user. The argument is ignored.

FPI(X) Multiple of PI

Returns X洒 $(\pi=$ 3. 14159...).

where "DUM" is any variable, "N" specifies the ADC ( 1 or 2), and "TIM" is the desired live-count time in seconds. The count time will be truncated to the nearest 0.1 sec. For example, if one used

$$
\text { SET } X=F A D C(1,10,35) \text {, }
$$

ADC 1 would be enabled for a live-time of $10.3 \mathrm{sec}$. If the truncated value of the first argument is other than 1, ADC 2 will be selected. Error ? ?27 will

TABLE III

MCA FOCAL EXTERNAL FUNCTIONS

Function

$\operatorname{FADC}(\mathbb{N}, T)$

$\operatorname{FSTP}(N)$

$\operatorname{FTIM}(\mathrm{N})$

FPSH(N)

FRSW(N)

FZER(LOW, HI)

$\operatorname{FCUR}(N, X)$

FDTP(N)

FMCA(CHAN, VAL) Stores or retrieves MCA data.

FSWH(N)

FRDC()

FPRC(X)

FODT (N)

FIDT(N)

$\operatorname{FPLT}(\mathrm{N}, \mathrm{X}, \mathrm{Y})$

FPPL(C, S, X, Y)

FCON(D,NC,N1,N2) Control function for plotter

$\operatorname{FCOM}(\mathrm{X}, \mathrm{AC})$

FCNT(N) alphanumerics.

Enable ADC " $N$ " ( $N=1$ or 2) for " $T$ " seconds live-time.

Disables ADC "N" and returns the elapsed live-time in seconds.

Returns the elapsed live-ti:ne in seconds for ADC " $N$ ".

Returns nonzero value if control panel push button " $\mathrm{N}$ " has been pushed.

Returns position of rotary switch " $N "(N=1$ to 4$)$ on control panel.

Zeros data channel contents irom channel LOW to channel $\mathrm{HI}$.

Returns the channel location of the specified display cursor; may also be used to position cursors on expanded display.

TENNECOMP format DEC-tape I/O; I/O operation determined by value of " $\mathrm{N}$ ". switch " $\mathrm{N}$ " is on.

Reads an ASC II character from the user's input device and converts it to a decimal number.

Converts $X$ to an ASCII character and prints it on the user's output device.

Set output .DAT slot to N. Set input .DAT slot to $\mathrm{N}$. Plotter line drawing function. Point plotting function.

Executes machine language instruction " $\mathrm{X}$ " with accumulator set to "AC"; returns value of accumulator after instruction executed.

Simulated skip counter used in conjunction with FCOM.
Returns nonzero value if sense 
be issued if "TIM" is less than zero or greater than 26, 214.3. If the selected ADC has already been enabled (as, for example, from the control panel), error message ? ? 8 will be issued.

B. FSTP

The ADC specified by the single argument of this function is disabled and the function returns the elapsed live-time in seconds (to the nearest 0.1 sec) of the specified ADC. For example, the command

TYPE FSTP(2), !

will disable ADC 2 and print the live-count time on the user's output device. An argument value other than 2 will select ADC 1.

C. FTIM

This function returns the elapsed live-time of the specified ADC without altering the status (enabled or disabled) of the ADC. Example:

TYPE FTIM(1), FTIM(2), :

D. FPSH

This function is used to interrogate the control panel push buttons ( $P 1$ thru $P 8)$. Each time a push button is depressed, a software flag is set indicating which button was depressed. A function call of the form

SET VAR=F PSH(N)

will set "VAR" to a nonzero value if the button specified by " $N$ " ( $N=1$ to 8 ) was the last button depressed and the flag will be reset to zero. If, however, button " $\mathrm{N}$ " was not the last one depressed, "VAR" will be set to zero and the flag will remain unchanged. No error messages are issued.

E. FRSW

The control panel rotary switch specified by the function argument ( 1 to 4 ) will be read and a value from 1 to 12 corresponding to the switch position will be returned. For example, the statement

$$
01.50 \text { IF (FRSW(2)-6) 1.6,1.7,1.8 }
$$

will cause a program branch to statement 1.6 if rotary switch $R 2$ is set at any position from 1 to 5 , branch to 1.7 if it is at position 6 , and branch to 1.8 if it 25 at a position greater than 6 . If the function argument after truncation is less than 1 or greater than 4, the error message ? ?27 will be issued.

F. FZER

This function is used to zero the data region starting with the channel specified by the first argument thru the channel specified by the second argument. For example, SET DUM=FZER(0, 1023) will zero the first 1024 data channels. If the function arguments are out of range (less than 0 or greater than 4095), or if the value of the second argument is less than the first argument, the error message ? 27 will be issued.

G. FCUR

The channel location of the display cursor specified by the first function argument ( 1 or 2) will be returned by calls to FCUR. For example,

TYPE FCUR(1), FCUR(2), :

will print the channel locations of the lower and upper cursors on the user's output device. Also, the statement

SET DUM =FZER(FCUR(1), FCUR(2))

could be used to zero the data region bracketed by the two cursors. If the truncated value of the first argument is other than 2, the position of cursor 1 (lower) will be returned.

A second (nonzero) argument may be used to position the specified cursor on the expanded display; if the display is not in EXPAND mode (FCP switch S7 on), the second parameter will be ignored. The origin for the expanded display will be set automatically to 20 channels below the specified Iocation of the lower cursor. For example, the call

$\operatorname{SET} \quad \mathrm{DUM}=\operatorname{FCUR}(1,642)+\operatorname{FCUR}(2,650)$

wil: set the origin of the expanded display to channe1 622, and position the upper and lower cursors at channels 650 and 642 respectively. (Remember that only 128 channels are displayed in the EXPAND mode.) If the value of the second parameter is negative or greater than 4095 , the error message ? ?27 will be issued. 
H.

FDTP

This function is used to perform DEC-tape input/output using a special binary file format that is compatible with other PDP-9/PDP-15 Tennecomp data acquisition programs. The file directory is stored in tape blocks 2,3 , and 4 , and data are stored in blocks 32-543. A 4096-word data file is stored in 16 consecutive blocks; up to 32 files may be stored on a single DEC-tape. A maximum of 72 characters may be used to describe each file. However, only the first six characters are used to identify a file and must therefore be unique for each file. DAT Slot 2 is used for data $1 / O$ and will normally be assigned to DEC-tape unit 2 .

The DEC-tape routines are called by a statement of the form

\section{SET DUM $=F D T P(N)$.}

Parameter " $\mathrm{N}$ " determines the operation to be performed as follows:

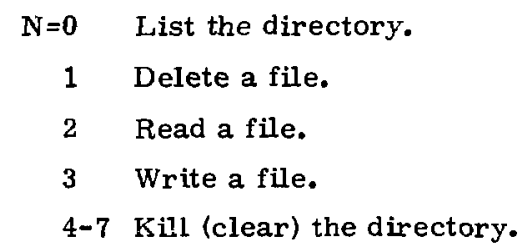

Only 3-bits of the truncated value of " $N$ " are used; therefore $N=8$ has the same effect as $N=0, N=9$ corresponds to $\mathrm{N}=1$, etc. Each operation is described in detail in the following paragraphs.

1. Directory Listing ( $\mathrm{N}=n)$. The data tape directory will be listed. The listing device will normally be the teletype, but may be changed to another device such as the line printer by use of the "OPEFATE" instruction or the function FODT.

\section{Delete a File $(N=1)$. The user will be} asked to specify a file to be deleted by typing the first six characters of the file description. If the specified file is not on tape, the nonfatal error message "NOT ON TAPE" will be typed.

3. Read a File ( $N=2)$. The data file specified by typing the first six characters of the file description will be read into the $4 \mathrm{~K}$ data region of memory. The message "NOT ON TAPE" will be typed along with the fatal error ? 34 if the file is not on the tape.

4. Write a File $\left(\mathrm{N}^{\mathrm{N}}=3\right)$. The user will be asked to type the file description which may consist of up to 72 characters. * This information will be entered in the directory, and the entire $4 \mathrm{~K}$ data region of memory will be written on tape. The message "TAPE FULL" and fatal error ? ?34 will be typed if the directory is full.

\section{Kill the Directory $(\mathrm{N}=4$ to 7$)$. If this op-} eration is specified, the message "DO YOU REALLY WANT TO DESTROY THE DIRECTORY?" will be typed. If the character " $Y$ " is typed in response, all file names in the directory will be deleted; any other character typed will cause the operation to be ignored.

6. Correction of Typing Errors. If a typing error is made during the typing of file names for the DELETE, READ, or WRITE operations, a CTRL/U may be typed to delete the present input line, which may then be retyped. Rubouts may not be used to delete single characters. (In all other cases, rubouts may bo used in the normal way.)

7. Examples of the Use of FDTP. The following examples are presented to help clarify the use of the function FDTP.

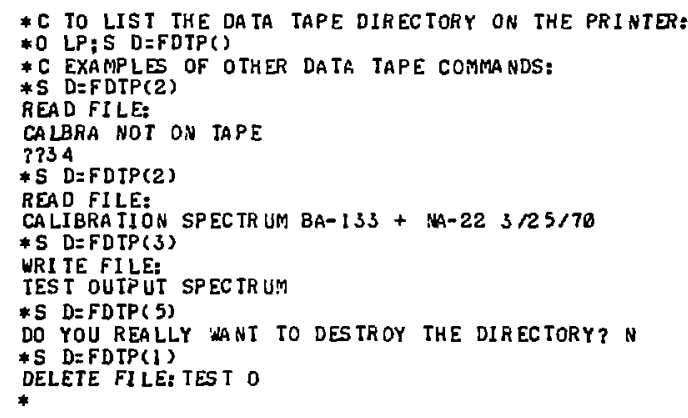

\footnotetext{
*Except the 11th file name which may contain only 48 characters and the 22 nd file name which may contain only 24 characters. This restriction is a result of the fact that only one block of the tape directory is read at a time in order to conserve core space.
} 
I. FMICA

This function gives the programmer access to the 4096 -word data region of computer memory. There are two possible calls to this function:

SET $V A R=F M C A(C H A N)$

and

\section{SET VAR $=$ FMCA $($ CHAN, VAL)}

In the first type of call, "VAR" will be set equal to the number contained in the data channel specified by "CHAN" ( $0 \leq \mathrm{CHAN} \leq 4095$ ). The second type of call sets the data channel specified by "CHAN" equal to "VAL"; "VAL" must be positive and no larger than 262,143 . If either parameter is not within the proper range, error ? ?27 will be issued. Function FMCA may be called recursively; for example, the statement
M. FODT

FODT is used to change the output device used by MCA FOCAL. The form of the function call is:

\section{$\operatorname{SET}$ DUM=FODT $(\mathrm{N})$,} where "DUM" is any variable and " $\mathrm{N}$ " is the . DAT slot number of a valid output device (refer to Appendix $B$ for .DAT slot assignments).

N. FET

This function is used to change the input - DAT slot, in the same manner that FODT is used to change the output . DAT siot.

O. FPLT, FPPL, and FCON

These functions are used for plotter graphics and are described in detail in Chap. $V$ of the FOCAL LSL Programming Manual. FPLT is the basic

FOR $I=1024,2047 ;$ SET $X=F M C A(I-1024,[F M C A(I)-0.5 * F M C A(I+1024)])$

could be used to set the contents of the first 1024 data channels equal to the contents of the second 1024 channels minus one-half the contents of the third 1024 channels.

J. FSWH

This function is used to determine if a "sense switch" (one of the console accumulator switches) is turned on. If the switch specified by the function parameter (0 to 17) is on, th 2 function returns a nonzero value; if the specified switch is off, zero is returned.

K, FRDC

This function reads an ASCII character from the input device (normally the teletype) and converts it to a decimal number. A function argument is not required.

L. FPRC

The function argument is converted to an ASCII character and printed on the output device. The reader is referred to Chap. IV of the FOCAL LSL Programming Manual for details on the use of FRDC and FPRC. function for controlling the plotter and FPPL is used to plot special characters. Alphanumeric output to the plotter is accomplished by the standard TYPE command preceded by a call to FODT(7) and one or more calls to the special control function FCON.

P. FCOM

This function allows the MCA FOCAL user to execute any single machine language instruction. In the call

SET ACF = FCOM(INS, ACI)

"ACI" will be loaded into the accumulator before executing the instruction, "INS" is the decimal equivalent of the instruction to be executed, and "ACF" will be set equal to the content of the accumulator after the instruction has been executed. (If "ACI" is omitted, the accumulator will be zeroed prior to executing the command.) For example, the call

\section{SET DUM=FCOM(229380)}

could be used to execute the instruction to disable the real-time clock (octal code 700004) and hence 
disable the display. Several examples of us eful instructions and their decimal equivalents are given in Table IV.

Q. FCNT

This function is used in conjunction with

FCOM to reference a counter that is incremented whenever the instruction executed by FCOM produces a skip. The calling format is:

\section{SET CNT $=F C N T(N)$}

The variable "CNT" will be set equal to the contents of the skip counter; if " $\mathrm{N}$ " is nonzero, the counter will be reset to zero.

TABLE IV

EXAMPLES OF SOME INSTRUCTIONS THAT MAY BE EXECUTED BY FUNCTION FCOM

\begin{tabular}{|c|c|c|}
\hline Octal Code & $\begin{array}{c}\text { Decimal } \\
\text { Equivalent } \\
\end{array}$ & Use \\
\hline 700004 & 229380 & $\begin{array}{l}\text { Disable the real- } \\
\text { time clock. }\end{array}$ \\
\hline 700044 & 229412 & $\begin{array}{l}\text { Enable the real-time } \\
\text { clock. }\end{array}$ \\
\hline 704031 & 231449 & $\begin{array}{l}\text { Turn on FCP lamp } \\
\text { L1. }\end{array}$ \\
\hline 704131 & 231513 & $\begin{array}{l}\text { Turn on FCP lamp } \\
\text { L2. }\end{array}$ \\
\hline 704231 & 231577 & $\begin{array}{l}\text { Turn on FCP lamp } \\
\text { L3. }\end{array}$ \\
\hline 704034 & 231452 & $\begin{array}{l}\text { Turn off FCP lamp } \\
\text { L1. }\end{array}$ \\
\hline 704134 & 231516 & $\begin{array}{l}1 \text { urn off FCP lamp } \\
\text { L2. }\end{array}$ \\
\hline 704234 & $23158 u$ & $\begin{array}{l}\text { Turn off FCP lamp } \\
\text { L3. }\end{array}$ \\
\hline 704712 & 231882 & $\begin{array}{l}\text { Read FCP toggle } \\
\text { switches S1 thru S8. }\end{array}$ \\
\hline 750004 & 249860 & $\begin{array}{l}\text { Load the accumula- } \\
\text { tor from the accumu- } \\
\text { lator switches. }\end{array}$ \\
\hline
\end{tabular}

\section{MCA FOCAL PROGRAM EXAMPLE}

A FOCAL program that performs simple dat: analysis and various $1 / O$ functions in response to teletype commands is listed in Appendix A. The program consists of three segments that are loaded from a FOCAL library tape by the LIBRARY IN command. The main program is loaded by typing

\section{LIBRARY IN PHA}

After PHA is loaded, it asks the user to type a command. A listing and explanation of the ten available commands may be obtained by typing "HELP". The FOCAL program PHACMD will then be loaded by PHA from the library tape, and a description of the commands given on the teletype or line printer as specified by the user. At the completion of PHACMD, program PHA will be reloaded automatically.

If "PLOT" is typed in response to PHA's request for a command, the FOCAL program PHAPLT will be loaded and the user may make linear, square root, or logarithmic plots of selected regions of data. An example of a plot produced by this program is shown in Fig. 2. At the completion of plotting, PHA will be reloaded.

The area, centroid, and full-width at halfmaximum (FWHM) of a spectral peak bracketed by the display cursors may be obtained by typing "AREA" in response to PHA's command request. Contents of channels on each side of the peak, as defined by the cursor locations, are averaged to calculate the background to be subtracted in order to obtain the net area under the peak. The number of channels averaged on each side of the peak is determined by the variable "BCH". Initially, $\mathrm{BCH}$ is set equal to 4 , but its value may be redefined at any time by stopping the program (by using a CTRL/P) and using the FOCAL "SET" command. The PHA program may then be reentered by typing "GO". The number of channels used in the background subtraction is properly taken into account when the statistical uncertainty of the net area is calculated. If the peak sits on a relatively smooth background. 


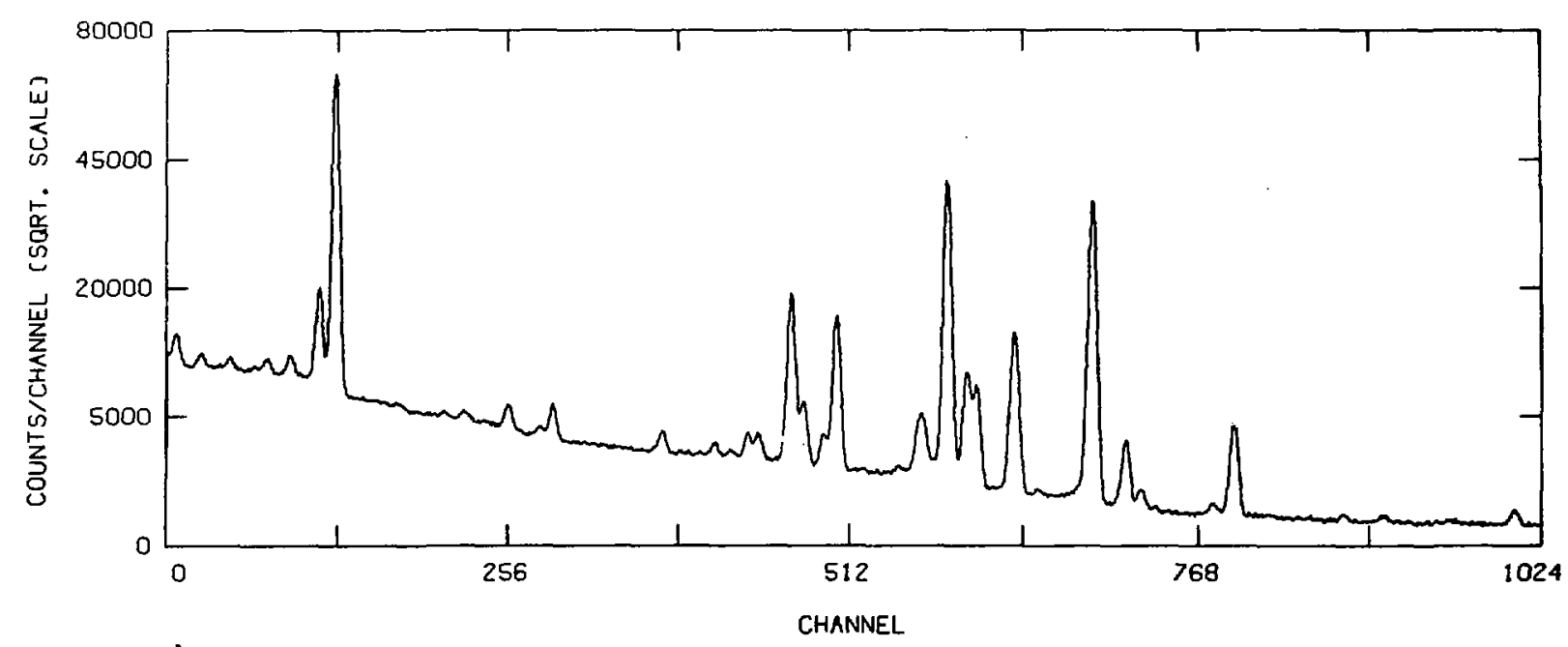

Fig. 2. Sample plot produced by PHAPLT.

the statistical uncertainty may be reduced by averaging over more channels to obtain the background.

The peak location is determined by calculating the peak centroid, $\bar{n}$, as follows:

$$
\bar{n}=\frac{\sum_{n=c_{1}}^{c_{2}} n_{n} \cdot k_{n}}{\sum_{n=c_{1}}^{c_{2}} k_{n}},
$$

where $c_{1}$ and $c_{2}$ are the cursor locations, and $k_{n}$ is the content of the nth channel corrected for background as follows:

$$
k_{n}=Y_{n}-(a+b \cdot n),
$$

where $Y_{n}$ is the content of the nth channel, and the constants $a$ and $b$ are determined from the background on each side of the peak. The peak FWHM is obtained from

$$
F W H M=2.3548 \sqrt{\sigma^{2}}
$$

where

$$
\sigma^{2}=\frac{\sum_{n=c_{1}}^{c_{2}} k_{n} \cdot(n-\bar{n})^{2}}{\sum_{n=c_{1}}^{c_{2}} k_{n}}
$$

and $\bar{n}$ is the centroid calculated from Eq. (1). Both Eqs. (1) and (3) assume that the peak is Gaussian; poorly shaped or partially unresolved peaks will produce anomalous results for the peak location and FWHM.

Program PHA is not intended to be a completely general purpose pulse height analysis program, but rather to illustrate some of the things that may be accomplished within the MCA FOCAL environment. The modular structure of PHA does, however, allow it to be easily modified (within the limits of available core) to perform other calculations or operations required for a particular application. 


\section{ACKNOWL.EDGMENTS}

The helpful suggestions and comments made by Walter R. Burrus of Tennecomp Systems and Ronald H. Augusts on of LASL during the development and debugging of the software described in this report are gratefully acknowledged.

\section{PEFERENCES}

1. L. V. East, "FOCAL LSL Programming Manual, " Los Alamos Scientific Laboratory report LA-4983-MS (1972).

2. "Advanced Monitor Software System for PDP-15/20/30/40, " Digital Equipment Corporation Manual DEC-15-MR2B-D (1970).

3. "PDP-15 FOCAL Programming Manual," Digital Equipment Corporation Manual DEC15-KJZA-D (1969).

APPENDIX A

LISTING OF PHA PROGRAM

\section{MAIN PROGRAM}

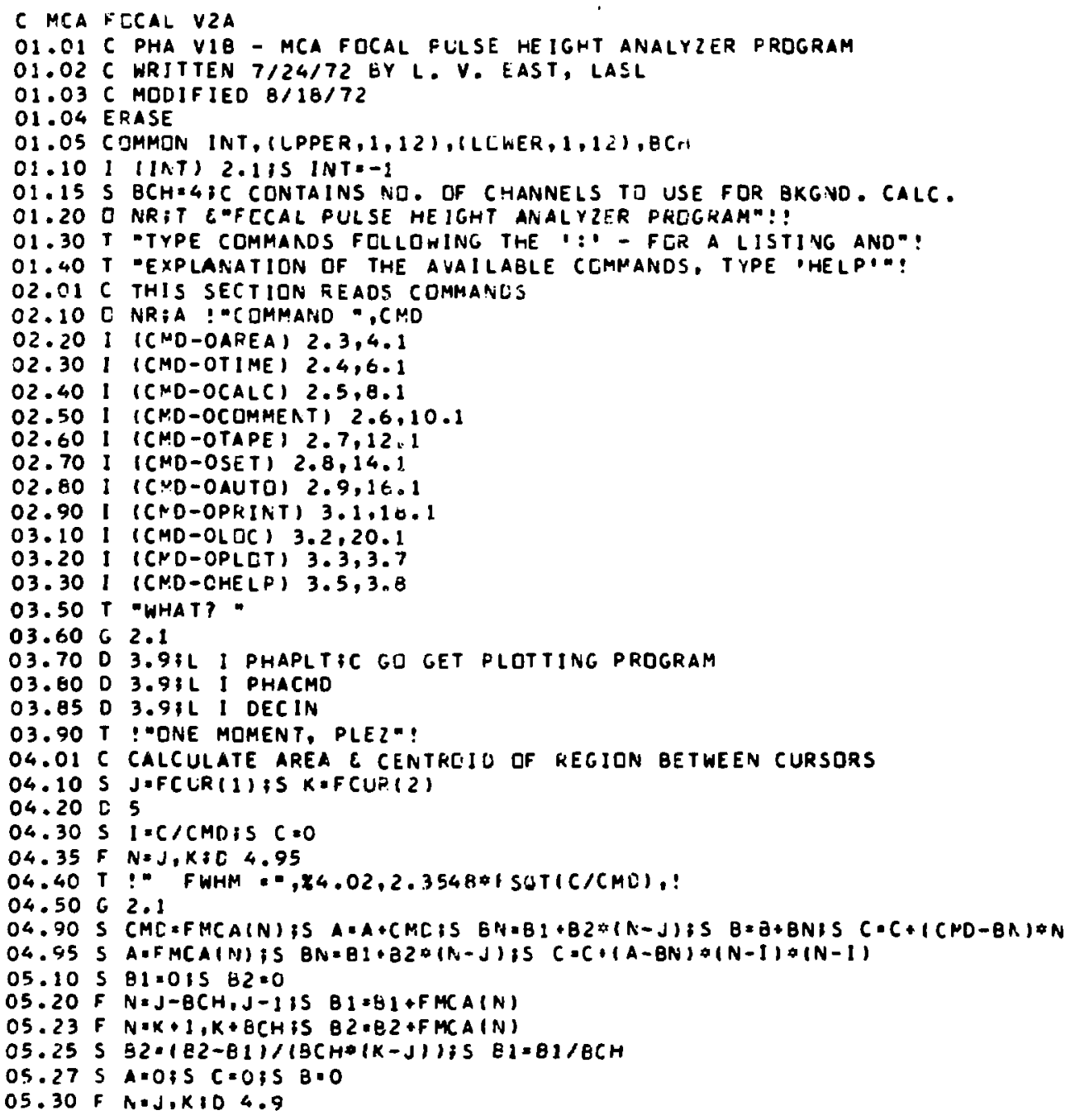




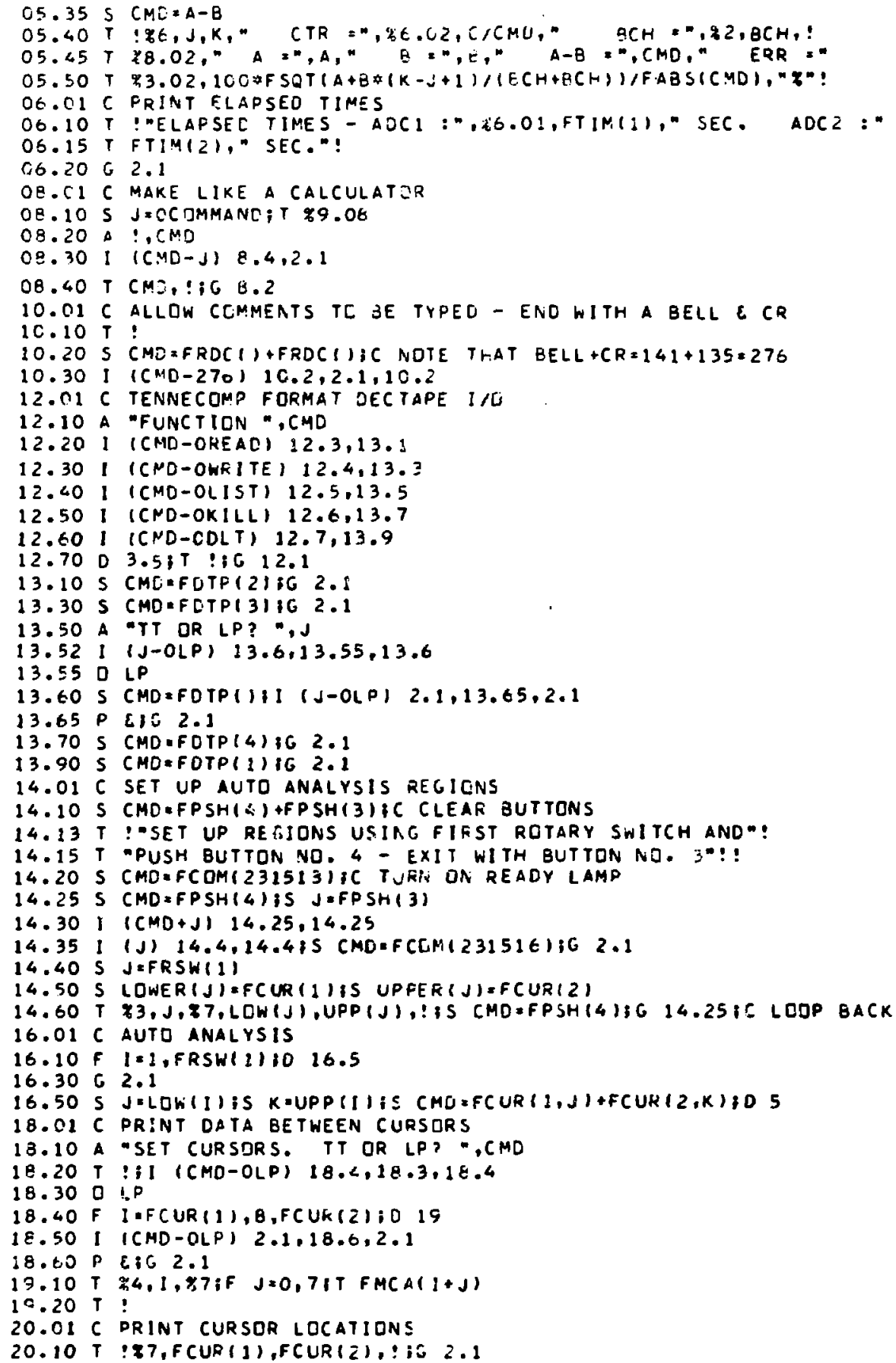

II. ROUTINE PHACMD

: MCA FECAL VZA

01.01 C EXPLAINJ COMMANOS USEC BY PHA PREGRRM

01.02 C L. V. EAST - 7/25/72

$01.63 \mathrm{C}$

01.10 C NR;T !!"CCMMANOS FJR FHA PRDGRAM":

01.20 a "OJ YQU WANT OUTPUT GN THE LINE FRINTER? IYES OR NOI ", ANS

$01.30 \mathrm{~T} !$ II (ANS-CYES) $1.4,1.33,1.4$

01.35 J LP 


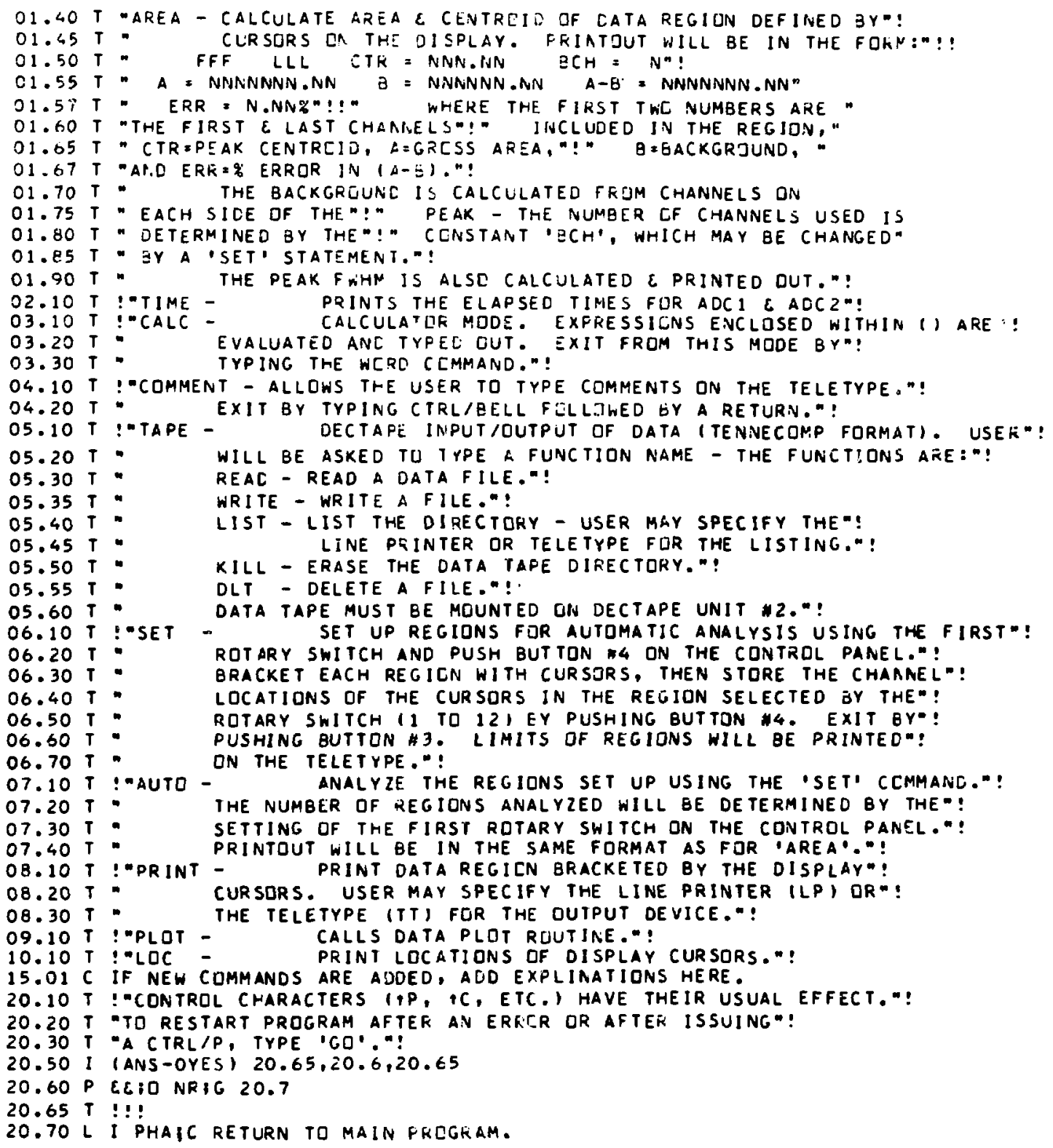

III. ROUTINE PHAPLT

C MCA FOCAL VZA

01.01 C PHAPLT VIA - L. EAST, 7/22

$01.03 \mathrm{C}$

01.04 Q NR; : :- SPECTRUM PLOTTING PROGRAM":!

$01.06 S \quad X E F=200$ iS $Y C F=200$;S YMG $=6 C O+Y E F$

01.10 A $x$-AXIS LENGTH IINCHESI? ", $x: S$ XNG $=x: 100+\lambda[F$

01.20 A "FIRST CHANAEL ND.? "IHNX

01.30 A MHCW MARY CHANNELS? " NCP

01.40 A "LIN, LCG, ER SQRT: ",TYP

01.42 I (TYP-OLIN) $1.43,1.45$

01.43 I (TYP-OLEG) $1.44,1.46$

01.44 I (TYP-OSORT) $1.4,1.47,1.4$

01.455 TYP $=5 ; 61.5$

$01.46 \mathrm{~S} T Y P=6 \$ 61.5$ 


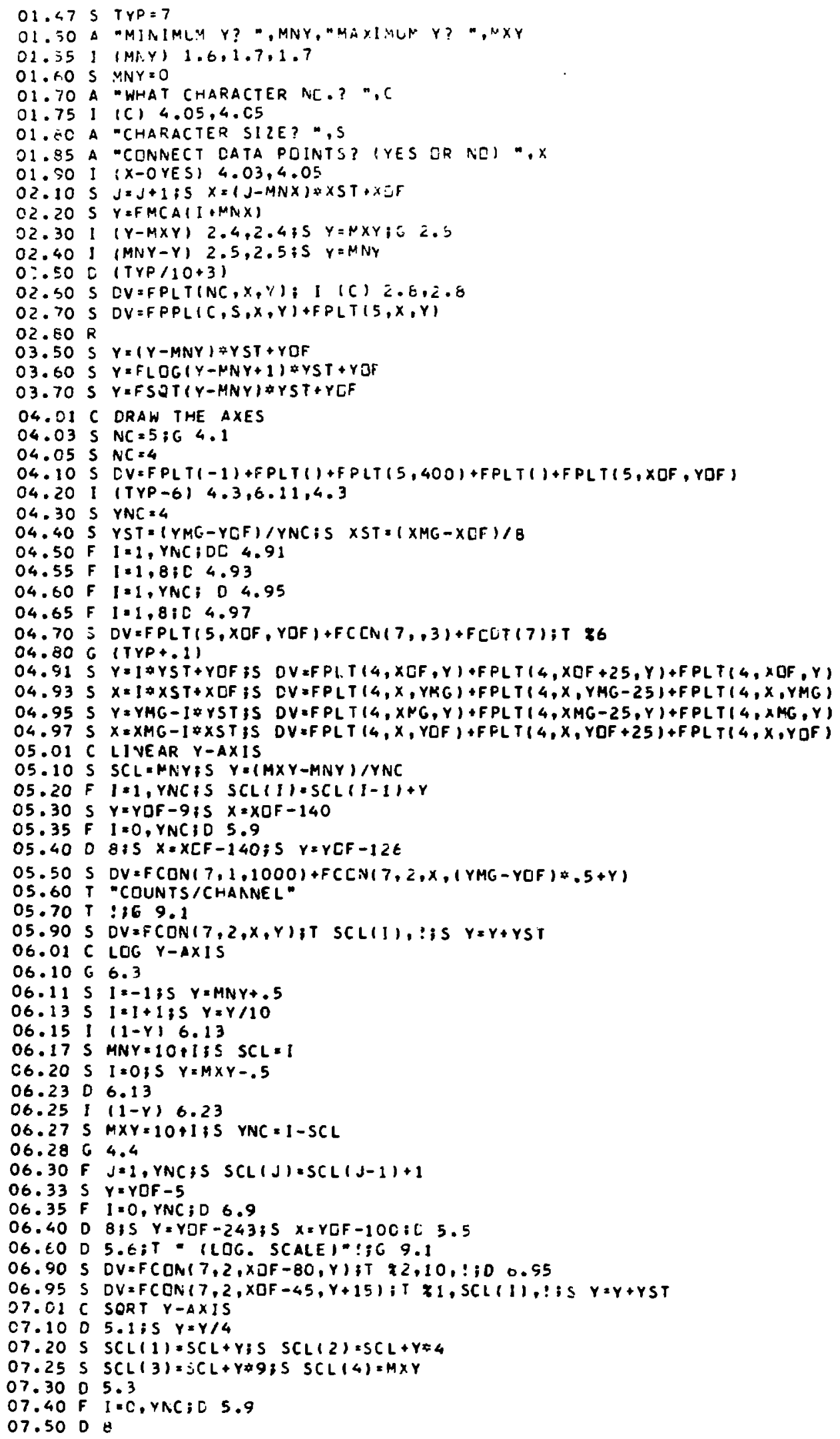




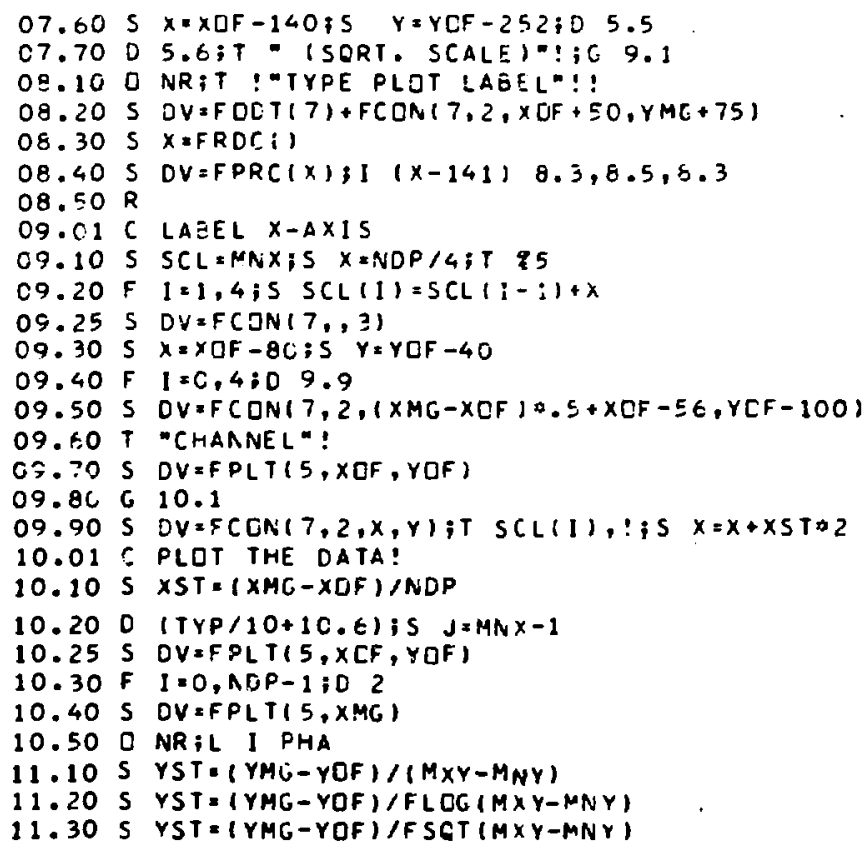

APPENDIX B

LOADING AND RUNNING MCA FOCAL

\section{GENERAL INFORMATION}

MCA FOCAL is supplied on DEC-tape as a binary file named "MFOCAL". This file is actually a library file containing the programs DATBLK, FOCALM, FSUBM, and TP3005, which are described in Appendix C. An additional binary file named "FAKIT" is also supplied for use in place of the library routine "ALPHA" as described in Sec. III. The .DAT Slots used by MCA FOCAL along with recommended handler assignments are given in Table B-I. Except for the FOCAL library and DEC-tape data .DAT Slots, all .DAT Slots not required may be assigned to the conscle teletype (T $\therefore$ A handler).

\section{The QDUMP region of the MCA FOCAL} DEC-tape contains a core-dump of MCA FOCAL with the "standard" .DAT slot assignments shown in parentheses in the last column of Table B-1. This "Dump-file" may be loaded as described in Sec. II. The system linking-loader may be used to
TABLE B-I. MCA FOCAL .DAT SLOT USAGE

\begin{tabular}{|c|c|c|c|}
\hline DAT Slot & Usage & \multicolumn{2}{|c|}{ Handler } \\
\hline-15 & Paper tape output & PPA, TTA & (TTA) \\
\hline-14 & Paper tape input & PRB, TTA & (TTA) \\
\hline-4 & Linking loader & DTE & (DTEI) \\
\hline-3 & Teletype output & TTA & \\
\hline-2 & Teletype input & TTA & \\
\hline-1 & System library & DTE & (DTEO) \\
\hline 2 & DEC-tape Data ${ }^{a}$ & DTE & (DTE2) \\
\hline 3 & $\begin{array}{l}\text { FOCAL library in- } \\
\text { put }\end{array}$ & DTE & (DTE1) \\
\hline 4 & $\begin{array}{l}\text { FOCAL library out- } \\
\text { put }\end{array}$ & DTE & (DTE1) \\
\hline 5 & Card input & CDB, TTA & (TTA) \\
\hline 7 & $\begin{array}{l}\text { Plotter alphanu- } \\
\text { merics }\end{array}$ & IPA, TTA & (IPA) \\
\hline 10 & Line printer & LPA, TTA & (LPA) \\
\hline
\end{tabular}

\footnotetext{
Tennecomp flle format.
} 
load the binary file MFOCAL if other than the standard I/O assignments are required. Note, however, that there is not enough core available in a $16 \mathrm{~K}$ system for more than one $1 / O$ handler in addition to TTA, DTE, and IFA to be loaded. A method of circumventing this restriction is given in Sec. III.

\section{II. "DUMP-FILE" LOAD}

A core-image of MCA FOCAL with standard I/O assignments may be loaded from the QDUMP area of the MCA FOCAL DEC-tape as follows:

1. Load Monitor by typing CTRL/C, or by use of the Monitor bootstrap.

2. Mount the MCA FOCAL DEC-tape on unit *1, and turn on the REMOTE switch.

3. Turn on the line printer and place it ONLINE.

4. After Monitor types a "\$", type "GET 1 30000 " followed by a carriage return.

5. MCA FOCAL will be loaded into core, identify itself, and type an asterisk.

MCA FOCAL is now ready for use; the FOCAL library tape (if different from the MCA FOCAL tape) should be placed on DEC-tape unit 1, and a data tape placed on unit 2.

\section{DELETING PLOTTER ALPHANUMERICS}

The library routine that handles plotter alphanumerics, "ALPHA", may be replaced by the much shorter 1 'tine "FAKIT" in order to make more core available for I/O handlers or FOCAL programs. For example, the card reader and line printer handlers may both be loaded as follows:

\footnotetext{
The initial octal starting address of MCA $F O C A L$ is 30000 for a $16 \mathrm{~K}$ system, 40000 for a $20 \mathrm{~K}$ system, etc. As an alternate procedure, one could type "GET 1". and then a CTRL/S (†S) after the tape stops spinning.
}

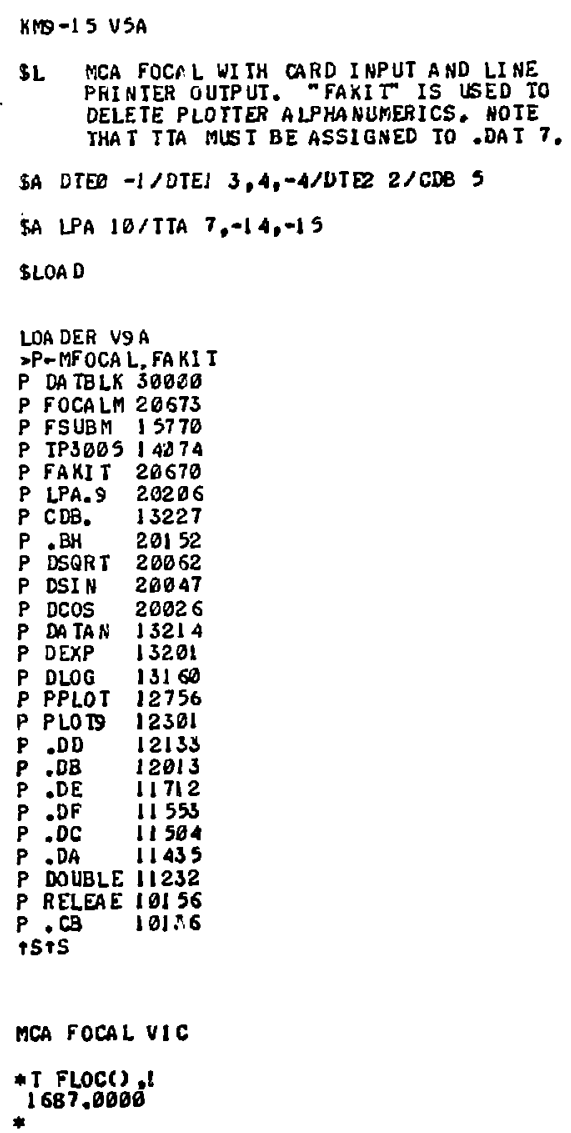

When FAKTT is used to replace ALPHA, any attempt to use the FOCAL function FCON will result in the error message ? 00. However, the functions FPIT and FPPL may still be used.

\section{CONTROL CHARACTER USE}

All standard control characters, including CTRL/C, may be used with MCA. FOCAL. When MCA FOCAL is initialized, the monitor bootstrap is transferred to a "save area" and the region of core normally cccupied by the bootstrap is overlayed by the data area. When a CTRL/C is issued, the bootstrap is restored and Monitor is then loaded in the normal manner. 
APPENDIX C

MCA FOCAL IMPLEMENTATION

I. HARDWARE REQUIREMENTS

MCA FOCAL is designed for use on a PDP9. PDP-9/L, or PDP-15 computer having the following minimum hardware configuration:

$16 K$ Memory
ASR-33 Teletype
2 DEC-tape drives
EAE
Real Time Clock
Display (34H or VP15)
Light Pen
Functional Control Panel (TP-1347)*
ADC Interface (TP-1517)*
2 Wilkinson-type ADCs

The ADC interface must be operated in the "ADD-1" mode, and the offset switches set to store data in the upper $4 \mathrm{~K}$ of computer memory. :*:*

In addition to the above required hardware, the following optional devices may also be utilized:

Additional $4 \mathrm{~K}$ memory increments

Line Printer

Card Reader

High Speed Paper Tape Reader and Punch

Incremental Plotter

Power Fail Protect

DEC-Disk

\section{SOFTWARE REQUIREMENTS}

All software required for operation with the above hardware is contained in the MCA FOCAL Operating System, consisting of a System Tape and the programs FOCALM, DATBLK, FSUBM, TP3005, and FAKIT. This software is described in the following paragraphs.

*Tennecomp Systems, Inc., Oak Ridge, Tennessee.

*: Interface units originally designed for $8 \mathrm{~K}$ systems may require modifications in order to store data in the proper region of memory.

\section{A. System Tape}

The system tape supplied with MCA FOCAL contains the standard DEC V5A Bank Mode Monitor, reconfigured for use with the above hardwar.. All nonstandard library routines required by MCA FOCAL for plotting, etc., have been included in the system library. The standard DEC MACRO assembler, FORTRAN IV Compiler (F4S), EDITOR, etc., are also on the tape. In addition, a system program named DAPBS is included that will load a series of machine language data acquisition programs that are on the system tape starting at tape block 700 (8). B. FOCALM FOCALM is a slightly modified version of the single user FOCAL LSL interpreter. ${ }^{1}$ The source file of FOCALM may be conditionally assembled for use with different system configurations using the parameters listed in Table $\mathrm{C}-1$.

\section{TABLE C-I.}

\section{CONDITIONAL ASSEMBLY PARAMETERS FOR FOCALM}

\begin{tabular}{ll} 
Identifier & \multicolumn{1}{c}{ Use } \\
BANK & $\begin{array}{l}\text { Define BANK }=2,3, \text { etc. for } 24 \mathrm{~K}, \\
32 \mathrm{~K}, \text { etc. systems. Default assump- } \\
\text { tion is BANK }=1(16 \mathrm{~K}) .\end{array}$ \\
POWER & $\begin{array}{l}\text { Define POWER }=0 \text { if power fail re- } \\
\text { start is to be used. }\end{array}$ \\
PDP15 & $\begin{array}{l}\text { Define PDP15=0 for use with a Page } \\
\text { Mode PDP-15 Monitor System. }\end{array}$ \\
DDT & $\begin{array}{l}\text { Define DDT=0 to use Monitor's } \\
\text { - IOPS error routine; otherwise all } \\
\text { IOPS errors will be handled by }\end{array}$
\end{tabular}

\section{DATBLK}

Routine DATBLK is a dummy "main program" that reserves the upper $4 \mathrm{~K}$ of memory for data and then turns control over to FOCAL. DATBLK should be loaded into the highest available 4K memory bank. 
D.

FSUBM

FSUBM contains all of the external functions used by MCA FOCAL. New functions may be added or present functions deleted by following the procedures outlined for FNEW in Chap. VI of the FOCAL15 manual. $^{3}$

E.

TP3005

This routine handles the updating of the data display and interrogation of the control panel. It is entered via interrupts from the real time clock. This routine contains proprietary software developed by Tennecomp Systems, Inc., for use with their hardware, and is not generally available for systems not equipped with such hardware. However, a similar routine may be written for $s ; s t e m s$ not equipped with Tennecomp hardware using the following program format:

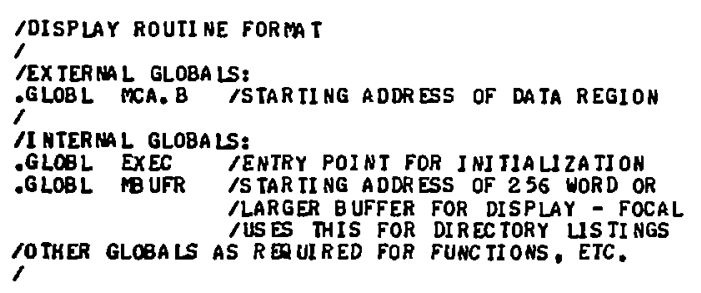

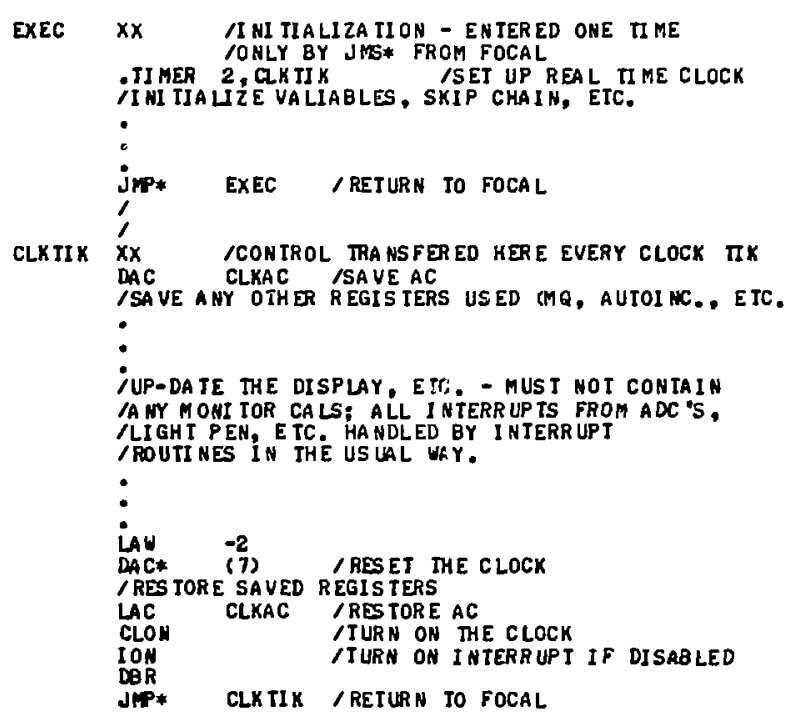

The appropriate sections of FSUBM must also be modified if no control panel is used, or if other than a TP-1517 ADC interface is used. F. FAKIT

This routine may be used to delete plotter alphanumerics, as described in Appendix B, in order to make more memory available (about 550 words) for FOCAL programs and/or I/O handlers. 